\title{
Migrende Görülen Belirtilerin Yaşam kalitesi ve Ağrı Şiddeti Üzerine Etkisinin İncelenmesi
}

\section{Investigation of theImpact of MigraineSymptoms on Life Quality and Pain Intensity}

\author{
Hatice ÖNTÜRK AKYÜZ 1*
}

Atıf Yapmak İçim: Akyüz HÖ. Migrende görülen belirtilerin yaşam kalitesi ve ağrı şiddeti üzerine etkisinin incelenmesi. Van Sag Bil Derg 2021,14,(2) 209-215.

https://doi.org/10.52976/van saglik.859024.

Geliș Tarihi:12/01/2021

Kabul Tarihi:04/06/2021

Basılama Tarihi: 30/08/2021
Bitlis Eren Üniversitesi, Sağlık Yüksek Okulu, Bitlis, TÜRKIYE.

* Sorumlu yazar: Hatice ÖNTÜRK AKYÜZ; E-mail: honturk@beu.edu.tr

\section{ÖZET}

Amaç: Araştırma, migren ataklarında yaygın olarak görülen belirti ve bulguların yaşam kalitesi ve ağrı şiddeti üzerine etkisini analiz etmek için yapıldı.

Materyal ve Metot: Çalışma, bir devlet hastanesi acil servisinde yapıldı. Araştırma, 4 Nisan 2017- 15 Ekim 2017 tarihleri arasında araştırmaya alınma kriterlerini karşılayan 70 hasta ile yürütüldü. Araştırmada elde edilen veriler, Hasta Bilgi Formu, Migrende 24 Saatlik Yaşam Kalitesi Ölçeği ve VAS (Görsel Analog Skala) kullanılarak toplandı. Çalışma öncesinde ölçek sahipleri ve kurumdan izin alındı. Etik kurul onayı, bir üniversite hastanesinin Girişimsel Olmayan Klinik Araştırmalar Etik Kurulundan alındı. Çalışmaya katılmayı kabul eden bireylerden bilgilendirilmiş onam alındı.

Bulgular: Araştırmada, gözlerde yaşarma, baş dönmesi ve bulantıya göre Migrende 24 Saatlik Yaşam Kalitesi Ölçeği ve Görsel Analog Skala'nın istatistiksel bakımdan anlamlı bir farklılık gösterdiği görüldü ( $<<0.05)$. Katılımcıların, iştahsızlık, aşırı idrar, titreme, çift görme, kusma, çarpıntı, kabızlık, geğirme, kilo kaybı ve nefes darlığına göre Migrende 24 Saatlik Yaşam Kalitesi Ölçeği ve Görsel Analog Skalanın istatistiksel olarak anlamlı bir farklılık göstermediği görüldü ( $p>0.05)$.

Sonuç: Gözlerde yaşarma, baş dönmesi ve bulantının hastaların yaşam kalitesi ve ağrı düzeyini etkileyen semptomlar olduğu belirlendi.

Anahtar Kelimeler: Migren, Ağrı şiddeti, Migren atağı, Yaşam kalitesi.

\begin{abstract}
Objective: This study was conducted to analyze the effects of symptoms and signs commonly seen in migraine attacks on quality of life and pain intensity.

MaterialandMethod: The research sample consisted of 70 patients. The data obtained in the study were collected using the Patient Information Form, the 24-Hour Quality of Life Scale in Migraine, and the Visual Analogue Scale. Permission was obtained from the scale owners and the institution before the study. Ethics committee approval was obtained from the Non-Invasive Clinical Research Ethics Committee of a university hospital.

Results: In this study, it was observed that the 24-Hour Quality of Life Scale and Visual Analogue Scale in Migraine showed a statistically significant difference according to tearing, dizziness and nausea $(\mathrm{p}<0.05)$. It was observed that the 24-Hour Quality of Life Scale and Visual Analogue Scale in Migraine did not show a statistically significant difference according to the participant's loss of appetite, excessive urine, tremors, double vision, vomiting, palpitations, constipation, belching, weight loss and shortness of breath ( $p>0.05)$. Conclusion: It was determined that tearing, dizziness and nausea in the eyes were symptoms affecting the quality of life and pain level of the patients.
\end{abstract}

Key Words: Migraine, PainIntensity, Migraine Attack, Quality of Life

\section{GİRIŞ}

Migren yüzyıllardır ülkemizde ve tüm dünyada en çok yakınılan baş ağrı durumu olarak bilinmektedir. Uluslararası baş ağrısı kriterlerine göre migren, ataklar şeklinde gelen, 4-72 saat kadar sürebilen, çoğunlukla tek taraflı, zonklayıcı ya da sıkıştırıcı tarzda, bulantı ve kusma, ışık ve koku hassasiyetinin olduğu, bireyin günlük yaşam kalitesini olumsuz etkileyen, şiddetli ve tekrarlayıcı baş ağrısı ataklarıdır (IHS, 2013; Tombul ve ark., 2015). Toplumda yoğun iş gücü kaybı ve yaşam kalitesini önemli ölçüde düşürmesine rağmen krizler halinde yaşanması ve ölüme sebebiyet vermemesi migrenin önemini azaltmaktadır (Yavuz ve ark., 2013). Bütün çalışmalar migrenin 
kadınlarda daha yüksek bir oranda görüldüğünü göstermektedir. Yapılan çalışmalar bu durumun kadın hastalarda hormonal değişikliklere bağlı olduğunu göstermektedir (Dikici ve ark., 2012; Özden ve ark., 2015). Yetişkinlerde, çoğunluğunu kadınlar oluşturmak üzere \%12 oranında görülmektedir (Izzati-Zade, 2008; İdiman, 2018). Ülkemizdeki duruma baktığımızda genel olarak \%16, kadınlar için \%25, erkekler için \%9 şeklinde bildirilmiştir (Linde, 2006; Ertaş, 2009). Migren, Dünya Sağlık Örgütü' ne göre iş yapmaya engel hastalıklar arasinda 19. sirada, kadın hastalarda ise 12. sirada yer almaktadır (Ünal, 2016). Yapılan bir çalışmada, baş ağrıları primer ve sekonder olarak ikiye ayrılmış ve sık görülen baş ağrılarının \% 90 oranında primer tipte ve çoğunlukla gerilim türü baş ağrısı şeklinde olduğu bulunmuştur. Gerilim tipi baş ağrılarını takiben çoğunlukla migren tipi baş ağrısı ortaya çıkmaktadır (Salomone ve ark., 2009; İdiman, 2018).

Sık yaşanan akut ya da kronik migren ataklarında, ağrıya eşlik eden bazı rahatsızlıklar da görülmektedir. Atak şiddetini artırdığı düşünülen bu belirtiler bireyden bireye veya aynı bireyde farklılık göstermektedir (Delice ve Ceylan, 2015). Bazı hastalarda belirtiler ağrı şiddetini ve süresini artırmaktadır (İdiman, 2018). Migren ağrısı her zaman aynı belirti ve bulgularla ortaya çıkmamaktadır. Ataklar farklı nedenlerle, farklı özelliklerde, farklı belirtilerle ve farklı zamanlarda ortaya ç1kabilir (Russel ve ark. 1994; Özden ve ark. 2015). Fiziksel hareketlerin migren ağrısını artırdı̆̆ 1 bilinmektedir. Vakaların büyük çoğunluğunda atak sırasında bulantı, bazen kusma, ışığa ve sese duyarlılık, halsizlik, huzursuzluk, burun akıntısı görülmektedir (IHS, 2013; Üçler, 2018).

Araştırma, akut ve/veya kronik migren atağına eşlik eden ve yaygın olarak görülen, ışık, ses ve koku tahammülsüzlüğü, gözlerde tek yada çift taraflı yaşarma, iştah kaybı, halsizlik, idrara çıkma sıklığı, zorlayıcı göğüs ağrısı, burun tıkanıkl1ğ1 veya burun akıntısı, el, kol ve bacaklarda titreme, baş dönmesi, görme bozuklukları (çift görme, görme kaybı, bulanık görme), bulantı ve/veya kusma, yutmada güçlük, konstipasyon ve ishal, göğüste çarpıntı hissi, hissizlik, işitmede güçlük veya geçici işitme kaybı, koordinasyon bozukluğu, dikkati toplayamama, yürümede dengesizlik, bulanık görme, sürekli yada aralıklı geğirme atakları, kilo kaybı, uyku problemleri, nefes alıp vermede güçlük ve uyuşukluk gibi migrende sıklıkla görülen belirti ve bulguların yaşam kalitesi ve ağrı şiddeti üzerine etkisini belirlemek için yapıldı.

\section{MATERYAL ve METOT}

Çalışma, bir devlet hastanesi acil servisinde yapıld. Veriler, 4 Nisan 2017- 15 Ekim 2017 tarihleri arasında toplandi. Araştırma, migren tanısı kesinleşmiş, migren şikâyeti ile acile başvuru yapan, migren veya diğer kronik hastalıklara karşı herhangi bir tedavi almayan, 18-50 yaş arası, okuma-yazma bilen, araştırmaya gönüllü olarak katılmayı kabul eden ve tanılanmıs nörolojik bir hastalığı olmayan 70 hasta ile yürütüldü.

\section{Verilerin toplanması}

Veriler, hasta acil kliniğe başvurduğunda, acil kliniğe gidilerek yüz yüze görüşülerek toplandı. Veri toplama formları hastaya verilerek ve gerekli açıklamalar yapılarak formları doldurması istendi. Formların doldurulması için hastaya yeterli süre tanindı. Veriler, Hasta Bilgi Formu, Migrende 24 Saatlik Yaşam Kalitesi Ölçeği (MYKÖ) ve Görsel Analog Skala (Visual Analog Scale - VAS) kullanılarak toplandi.

\section{Hasta bilgi formu}

Hasta bilgi formu, araştırmacı tarafından literatür doğrultusunda oluşturuldu. Hasta bilgi formunda, bireylerin demografik özellikleri, migren ataklarına ilişkin durumlar ve atak sırasında görülen belirtileri sorgulayan üç bölüm bulunmaktadır. 
Migrende 24 saatlik yaşam kalitesi ölçeği (MYKÖ)

Ölçek, Santanello ve Hartmaier (1995) tarafından geliştirilmiştir. Migrenli bireylerin yaşam kalitesindeki değişikliği kısa süreli olarak belirlemeyi amaçlayan bir ölçektir Ölçek, migren tipi baş ağr1sını gidermek için ilaç alımından sonraki 24 saat süresince yaşam kalitesindeki değişikliği ölçmektedir. Türk toplumu için geçerlilik ve güvenilirlik çalışmaları, İltuş tarafından 2007 yılında yapılmıştır. Migren baş ağrıları olan hastalarda kısa süreli yaşam kalitesini izlemek amaciyla kullanılabilmektedir (İltuş, 2007). Migrende 24 Saatlik Yaşam Kalitesi Ölçeği yedili Likert tip bir ölçek olup, toplam 15 soru bulunmaktadır. Ölçekte yaşam kalitesi alanına yönelik beş boyut bulunmaktadır. Her bir boyutta üç madde vardır.

\section{Görsel analog skala (Visual Analog Scale - VAS)}

Price ve ark. tarafından 1983 yılında geliştirilen ölçek hastada ağrının şiddetini ve ağrı düzeyini belirlemek için kullanılır. Bu ölçek, sayısal olarak ölçülemeyen bazı değerleri sayısal hale çevirmek amacıyla kullanılmaktadır. Bir ucunda ağrısızlık, diğer ucunda olabilecek en şiddetli ağrı yazan 10 $\mathrm{cm}^{\prime}$ lik bir cetvel üzerinde hasta kendi ağrısını işaretler. Test çok uzun süreden beri kendini kanitlamış ve tüm dünya literatüründe kabul görmüştür.

Araştırmada, Helsinki Deklarasyonuna uyuldu ve araştırma öncesi, Sağlık Bakanlığı tarafından kabul edilmiş bir üniversite hastanesinin Girişimsel Olmayan Klinik Araştırmalar Etik Kurulundan etik kurul onayı alındı (11.04.2017; No:05) alındı. Ayrıca kurumdan araştırma izni ve çalışmaya katılım gösteren hastalardan aydınlatılmış onam formu doldurularak izin alındı. Migrende 24 Saatlik Yaşam Kalitesi Ölçeği kullanabilmek için Türkçe'ye çevrilip Türkiye'de uygulanmasını sağlayan İltuş'tan kullanım izni alınmıştır.
İstatistiksel analiz: Çalışmada elde edilen bulgular değerlendirilirken IBM SPSS Statistics 22 (IBM SPSS Statisticsfor Windows, Version 22.0. Armonk, NY: IBM Corp.) paket programı kullanıldı. Gruplarının dağılımlarının normal olup olmadığına Kolmogorov-Smirnov testi ile bakıldı. Çalışma verileri değerlendirilirken tanımlayıcı istatistiksel (Ortalama, Standart sapma, Frekans, Yüzde) yanı sıra niceliksel verilerin gruplar arası karşılaştırılmasında bağımsız örneklem t-test ve niteliksel verilerin karşılaştırılmasında ise Chi-square (ki-kare) testi kullanılmıştır. Sonuçlar \%95'lik güven aralığında, anlamlılık anlamlılık $\mathrm{p}<0,05$ düzeyinde değerlendirildi.

\section{BULGULAR}

Araştırmaya katılan migren hastalar1nın $\% 74,28^{\prime}$ sının kadın ve $\% 25,72$ ünün erkek olduğu görülmüştür. Eğitim durumuna göre \%20'sinin okur yazar \%37,14'unun ilkokul mezunu, \%5,71'inin ortaokul mezunu, \%15,72'sinin lise mezunu, \%21,43'ünün üniversite mezunu oldukları görülmüştür (Tablo 1). Araştırmaya katılan migren hastalarının \%54,28'ünün ev hanı$\mathrm{m}$, \%20'sinin memur oldukları görülmüştür (Tablo 1).

Araştırmaya katılan migren hastalarında \%60 oranında ağrının gün içinde başlama zamanı düzensiz, \%8,57'sinin başlama zamanı sabah, \%14.28'ünün başlama zamanı öğlen, \%14.28'inin başlama zamanı akşam ve \%2,8'inin başlama zamanı gece olduğu belirlenmiştir (Tablo 1).

Araştırmaya katılan migren hastalar1nin \%37,14'ünün daha önce gördüğü bir tedavi yöntemi uygulandığı, \%62,86'sının daha önce gördüğü bir tedavi yöntemi uygulanmadığ1 görülmüştür $(\mathrm{p}<0.05)$ (Tablo 1). Araştırmaya katılan migren hastalarının \%51,42'ünün acile gelmeden önce ağr1 kesici aldığ almadığı görülmüştür (Tablo 1) ( $\mathrm{p}<0.05)$. 
Tablo 1. Hastaların demografik özellikleri

\begin{tabular}{|c|c|c|c|}
\hline Özellikler & & $\mathbf{n}$ & $\%$ \\
\hline \multirow{2}{*}{ Cinsiyet } & Kadın & 52 & 74,28 \\
\hline & Erkek & 18 & 25,72 \\
\hline \multirow{5}{*}{ Eğitim Durumu } & Okuryazar & 14 & 20 \\
\hline & İlkokul & 26 & 37,14 \\
\hline & Ortaokul & 4 & 5,71 \\
\hline & Lise & 11 & 15,72 \\
\hline & Üniversite & 15 & 21.43 \\
\hline \multirow{3}{*}{ Meslek } & Ev hanımı & 38 & 54,28 \\
\hline & Memur & 14 & 20 \\
\hline & Diğer & 18 & 25,72 \\
\hline \multirow{5}{*}{ Ağrının gün içi başlama zamanı } & Düzensiz & 42 & 60 \\
\hline & Sabah & 6 & 8,57 \\
\hline & Öğle & 10 & 14,28 \\
\hline & Akşam & 10 & 14,28 \\
\hline & Gece & 2 & 2,87 \\
\hline \multirow{2}{*}{ Daha önce uygulanan tedavi } & Evet & 26 & 37,14 \\
\hline & Hayır & 44 & 62,86 \\
\hline \multirow{2}{*}{ Acile gelmeden ağrı kesici alma } & Evet & 36 & 51,42 \\
\hline & Hayır & 34 & 48.58 \\
\hline Toplam & & 70 & 100.0 \\
\hline
\end{tabular}

istatistiksel olarak anlamlı bir farklılık göstermediğ $i$

Katılımcıların gözlerde yaşarma, baş dönmesi ve bulantı bakımından MYKÖ'nün istatistiksel olarak anlamlı bir farklılık gösterdiği görüldü (Tablo 2) ( $p<0.05)$. Göz yaşarması, baş dönmesi ve bulantısı olmayan hastaların migrende MYKÖ puan ortalamasının daha yüksek olduğu görüldü. Göz yaşarması, baş dönmesi ve bulantısı olanlardan daha yüksek olduğu görüldü. Benzer şekilde katılımcıların göz yaşarması, baş dönmesi ve bulantıya göre VAS'ın istatistiksel açıdan anlamlı bir farklılık gösterdiği görüldü (Tablo 2) ( $\mathrm{p}<0.05)$. Göz yaşarması, baş dönmesi ve bulantısı olan hastaların ağrı düzeyi gözlerde yaşarma, baş dönmesi ve bulantısı olmayan hastalara göre daha yüksek olduğu görüldü (Tablo 2) $(\mathrm{p}<0.05)$.

Katılımcıların, iştahsızlık, idrara çıkma sıklığı, titreme, çift görme, kusma, çarpıntı, kabızlık, geğirme, kilo kaybı ve nefes darlığına göre MYKÖ ve VAS'ın görüldü (Tablo 2) ( $\mathrm{p}>0.05)$.

Katılımcıların göğüs ağrısı, yutma güçlüğü, his kaybı, uyuşukluk, uykusuzluk, yutma güçlüğü ve bulanık görmeye göre MYKÖ'nün istatistiksel olarak anlamlı bir farklılık gösterdiği görüldü (Tablo 2) (p<0.05). Göğüs ağrısı, yutma güçlüğü, his kaybı, uyuşma, uykusuzluk ve bulanık görme bulgusu olmayan hastaların migrende 24 saatlik yaşam kalitesi olanlardan daha yüksek oranda bildirildi (Tablo 2) $(\mathrm{p}<0.05)$.

Ancak, katılımcıların göğüs ağrısı, yutma güçlüğü, his kaybı, uyuşukluk, uykusuzluk ve bulanık görmeye göre $\mathrm{VAS}^{\prime}$ ın istatistiksel olarak anlamlı bir farkl1lık göstermediği tespit edildi (Tablo 2) $(\mathrm{p}>0.05)$.

Katılımcıların burun tıkanıklı̆̆ına göre MYKÖ'nün istatistiksel olarak anlamlı bir farklılık göstermediği tespit edildi (Tablo 2) ( $\mathrm{p}>0.05)$. Ancak, katılımcıların burun tıkanıklığına göre VAS'ın istatistiksel açıdan 
anlamlı bir farklılık gösterdiği tespit edildi (Tablo 2) zeyi burun tıkanıklığı olmayan hastalara göre daha $(\mathrm{p}<0.05)$. Burun tıkanıklığı olan hastaların VAS dü- $\quad$ yüksek olduğu bildirildi.

Tablo 2.Migren belirtileri ile Migrende 24 Saatlik Yaşam Kalitesi Ölçeği (MYKÖ) ve Görsel Analog Skala (Visual Analog Scale, VAS) puanlaması ilişkisi.

\begin{tabular}{|c|c|c|c|}
\hline$\overline{\text { Migren Belirtileri }}$ & & MYKÖ & 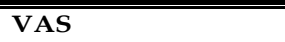 \\
\hline \multirow{3}{*}{ Göz Yaşarması } & Evet & $48(32.05)$ & $48(40.92)$ \\
\hline & Hayır & $22(43.02)$ & $22(23.68)$ \\
\hline & P değeri & 0.036 & 0.001 \\
\hline \multirow{3}{*}{ İştahsızlık } & Evet & $57(36.15)$ & 57 (35.68) \\
\hline & Hayır & $13(32.65)$ & $13(29.25)$ \\
\hline & P değeri & 0.175 & 0.657 \\
\hline \multirow{3}{*}{ Aşırı İdrar } & Evet & $28(32.07)$ & $28(35.80)$ \\
\hline & Hayır & $42(37.79)$ & $42(35.30)$ \\
\hline & P değeri & 0.250 & 0.918 \\
\hline \multirow{3}{*}{ Göğüs Ağrisı } & Evet & $6(29.23)$ & $26(40.52)$ \\
\hline & Hayır & $44(39.20)$ & $44(32.53)$ \\
\hline & P değeri & 0.048 & 0.110 \\
\hline \multirow{3}{*}{ Burun Tikanıklığı } & Evet & $38(56.92)$ & $38(6.71)$ \\
\hline & Hayır & $22(65.65)$ & $22(6.00)$ \\
\hline & $\mathbf{P}$ değeri & 0.717 & 0.020 \\
\hline \multirow{3}{*}{ Titreme } & Evet & $51(35.66)$ & $51(37.21)$ \\
\hline & Hayır & $19(35.08)$ & 19 (30.92) \\
\hline & P değeri & 0.916 & 0.246 \\
\hline \multirow{3}{*}{ Baş Dönmesi } & Evet & $64(33.05)$ & $64(37.08)$ \\
\hline & Hayır & $6(61.58)$ & 6 (18.67) \\
\hline & P değeri & 0.001 & 0.032 \\
\hline \multirow{3}{*}{ Çift Görme } & Evet & $41(32.82)$ & $41(38.88)$ \\
\hline & Hayır & $29(39.29)$ & $29(30.72)$ \\
\hline & $P$ değeri & 0.190 & 0.096 \\
\hline \multirow{3}{*}{ Bulantı } & Evet & $64(33.77)$ & $64(37.43)$ \\
\hline & Hayır & $6(53.92)$ & $6(14.92)$ \\
\hline & $P$ değeri & 0.020 & 0.009 \\
\hline \multirow{3}{*}{ Yutma Güçlüğ̈ü } & Evet & $37(54.58)$ & $37(6.54)$ \\
\hline & Hayır & $33(68.00)$ & $33(6.21)$ \\
\hline & $P$ değeri & 0.023 & 0.297 \\
\hline \multirow{3}{*}{ Kusma } & Evet & $44(35.06)$ & $44(36.34)$ \\
\hline & Hayır & $26(36.25)$ & $26(34.08)$ \\
\hline & P değeri & 0.813 & 0.650 \\
\hline \multirow{3}{*}{ Kabızlık } & Evet & $17(32.35)$ & $17(41.97)$ \\
\hline & Hayır & $53(36.51)$ & 53 (33.42) \\
\hline & P değeri & 0.464 & 0.129 \\
\hline \multirow{3}{*}{ Çarpıntı } & Evet & $40(61.12)$ & $40(6.48)$ \\
\hline & Hayır & $30(60.62)$ & $30(6.27)$ \\
\hline & $P$ değeri & 0.934 & 0.505 \\
\hline \multirow{3}{*}{ His Kaybi } & Evet & $46(31.12)$ & 46 (37.12) \\
\hline & Hayır & $24(43.90)$ & $24(32.40)$ \\
\hline & P değeri & 0.013 & 0.352 \\
\hline \multirow{3}{*}{ Uyuşma } & Evet & $53(30.78)$ & $53(37.74)$ \\
\hline & Hayır & $17(50.21)$ & $17(28.53)$ \\
\hline & P değeri & 0.001 & 0.102 \\
\hline \multirow{3}{*}{ Bulanık Görme } & Evet & $53(32.50)$ & $53(37.74)$ \\
\hline & Hayır & $17(44.85)$ & $17(28.53)$ \\
\hline & P değeri & 0.029 & 0.066 \\
\hline \multirow{3}{*}{ Geğirme } & Evet & $27(34.98)$ & $27(33.87)$ \\
\hline & Hayır & $43(35.83)$ & $43(36.52)$ \\
\hline & $P$ değeri & 0.866 & 0.592 \\
\hline & Evet & $21(39.64)$ & $21(41.76)$ \\
\hline Kilo Kaybı & Hayır & 49 (33.72) & 49 (32.82) \\
\hline & P değeri & 0.265 & 0.089 \\
\hline & Evet & $63(33.09)$ & 63 (35.72) \\
\hline Uykusuzluk & Hayır & $7(57.21)$ & $7(33.50)$ \\
\hline & P değeri & 0.003 & 0.782 \\
\hline & Evet & $29(30.05)$ & $29(39.95)$ \\
\hline Nefes Darlığı & Hayır & $41(39.35)$ & 41 (32.35) \\
\hline & P Value & 0.060 & 0.121 \\
\hline
\end{tabular}




\section{TARTIŞMA}

Araştırmada, kadın hasta oranı yüksek bulundu. Katılımcıların \% 74.28 ini kadın hastaların oluşturduğu görüldü. Literatür incelendiğinde benzer çalışmalara rastlandı. Delice ve Ceylan'ın yaptıkları çalışmada (2015) kadın hasta oranı \% 85 olduğu görülmüştür (Delice ve Ceylan 2015). Bir başka çalışmada ise, migren hastalarının demografik özellikleri incelenmiş ve Erkek/kadın oranı 1:5 olarak bulunmuştur (Eruyar ve ark., 2014). Ancak literatür incelendiğinde aksi yönde çalışmalara da rastlandı. Tombul ve arkadaşlarının yaptığı çalışmada (2015) hasta ve kontrol gruplarında bulunan bireylerin yaşı, cinsiyeti, eğitim düzeyi, gelir durumu gibi sosyal ve demografik özellikler karşılaştırıldığında gruplar arasında anlamlı farklılık bulunmadığı bildirilmiştir (Tombul ve ark., 2015).

Yapılan literatür çalışmaları migrenin her yaş grubunda görüldüğ̈ü, ancak özellikle 30-50 yaşlarda daha yüksek oranda tesbit edildiği bildirilmiştir (Sönmezler 2013; Polat ve Hocaoğlu, 2018;Yağmur ve ark. 2019). Younger ve ark.'nın (2016) yaptığ1 çalışmada hastaların yaşa göre anlamlı derecede değişkenlik gösterdiği, erkek ve kadın hastalarda yaş aralığ 35 ve 45 olarak bildirilmiştir (Younger ve ark., 2016).

Migren hastalarında sosyo - demografik özelliklerin incelendiği bir çalışmada, eğitim düzeyleri yükseldikçe migrene yaklaşımın daha bilinçli olduğu, ilaç tüketimi, erken tanı, doktor başvurusunda artış yönünde olumlu davranış şekillerinin gözlendiğini bildiren çalışmalar mevcuttur. Migren hastalarının demografik ve klinik özelliklerinin incelendiği bir çalışmada (2014) migren türü baş ağrısının evli ve eğitim düzeyi düşük kadınlarda daha sık görüldüğü tesbit edilmiştir (Eruyar ve ark. 2014). Garcia ve ark. nın (2016) Avusturya'da 150 hasta üzerinde yapılan bir çalışmada, 38 (\% 25,3) hasta ilkokul; 54 (\% 36) orta ögrretim ve 55 (\% 36,7) hastanın üniversite düzeyinde olduğu tesbit edilmiştir (Garcia, et al.2016). Ertaş ve ark.'nın yaptığı çalışmada (2012) migren prevalansının en yüksek olduğu grubun eğitimsiz grup olduğu $(\% 31,6)$ görülmüştür (Ertaş ve ark., 2012). Literatürde aksi yönde çalışmalar da mevcuttur Yapılan bir migren çalışmasında migreni olanlar ve olmayanların eğitim seviyesi arasında anlamlı bir fark bulunmadığı bildirilmiştir (Büyükyörük, 2017).

Migren atağı sırasında atak başladıktan sonra hastada; zonklama, mide bulantısı, kusma, ışık, ses ve dokunmada hassasiyet, bulanık görme, baş dönmesi, burun akıntısı, göz yaşarması ve daha farklı çok sayıda belirtinin ortaya çıtığı bilinmektedir. Bu durumun ağrı şiddetine bağlı olarak ortaya çıktığ söylenebilir. Literatürde benzer çok sayıda çalışmaya rastlanmıştır (Polat ve Hocaoğlu, 2018; Migren bulantı, kusma, fotofobi, fonofobi, görsel auralar, baş dönmeleri hatta afazi ve hemipleji gibi belirtilerin eşlik ettiği baş ağrısı ataklarıyla karakterize olduğu görülmektedir (Yağmur ve ark., 2019). Bu çalışmada migren atağı sırasında ortay çıkan bazı belirti ve bulguların yaşam kalitesini düşürdüğü ve ağrı düzeyini yükselttiği tesbit edildi. Ancak literatürde migren atağı ve görülen belirtiler arasındaki ilişkiye dönük sınırlı sayıda çalışmaya rastlanmıştır. Migren belirtilerinin, ağrı düzeyi ve yaşam kalitesine etkisini gösteren çalışmalara ihtiyaç bulunmaktadir.

\section{Sonuç ve Öneriler}

Çalışma sonucunda kadın hasta oranının yüksek olduğu, eğitim düzeyi düştükçe migren ataklarına bilinçsizce yaklaşıldığı ve ihmal edildiği, kadın hastalar arsında ev hanımlarında görülme oranının daha yüksek olduğu, migren ataklarında, gözlerde yaşarma, bulantı ve/ veya bulantı hissi ve baş dönmesi görülmeyen hastaların migrende MYKÖ ölçümlerinin daha yüksek olduğu, gözlerde yaşarma, bulantı ve baş dönmesi olan hastalarda VAS skorlarının daha yüksek olduğu bildirildi. Bu sonuçlar doğrultusunda çalışmanın en az üç (3) aylık süre ile ve daha geniş hasta grupları üzerinde yapılması önerildi.

\section{Çıkar Çatışması}

Yazarlar çıkar çatışması olmadığını beyan eder. 


\section{KAYNAKLAR}

Büyükyörük C. Migren Hastalarının Yaşam Kalitesi, Anksiyete ve Depresyon Düzeylerinin Değerlendirilmesi. Necmettin Erbakan Üniversitesi Meram Tıp Fakültesi Aile Hekimliği ABD. Uzmanlık Tezi.

Delice O, Ceylan M. Migren ilişkili baş dönmesi şikâyeti ile acil servise gelen migren hastalarınin değerlendirilmesi. Duzce Med J 2015; 17(3): 111-4.

Dikici S, Baltacı D, Yılmaz A, Sayı S, Kara İH. İlk basamak sağlık merkezine başvuran erişkin hastalarda baş ağrısının özellikleri ve etkili olabilecek etmenlerin belirlenmesi. Dicle Med J. 2012;39 (1):35-41.

Ertaş M, Baykan B, Orhan EK, Zarifoglu M, Karli N, Saip S, et al. Prevalance of migraine in Turkey: a nation wide home based study. J Neurol Sci 2009;148:465-74.

Ertas M, Baykan B, Orhan EK, Zarifoglu M, Karli N, Saip S, et al. One-year prevalence and the impact of migraine and tension-type headache in Turkey: a nation wide home-based study in adults. J Headache Pain . 2012;13(2):147-57.

Eruyar E, Genç, E, Genç, BO. Konya ilindeki migren hastalarının demografik ve klinik özellikleri. Selçuk Tıp Derg 2014;30(4): 162-4.

García-CaboFernández C, Sánchez-Lozano P, Pérez-Álvarez A, Martínez-Ramos JM, MartínezRodríguez L, Pascual J. Sociodemographic characteristics of a cohort of patients with chronic migraine from a health district in Asturias. Neurologia 2016;31(3):157-60.

IHS. Headache Classification Subcommittee of the International Headache Society. ICHD-3. Cephalalgia 2013; 33 (9), 629- 808.

Izzat1-Zade KF. The role of serotonin in the pathogenesis and clinical presentations of migraine attacks. Neurosci Behav Physiol 2008;38(5).

İdiman F. Migren baş ağrısı, tipleri, tanı ve tedavi. Turkiye Klin J Neurol 2018;11(1):28-4
Linde M. Migraine: A review and future directions for treatment. Acta Neurol Scand 2006;114:71-83.

Özden SY, Baykan B, Ertekin E. Migrenli hastalarda obsesif- kompulsif belirtilerin araştırılmaS1. Ağr1 2015;27(1):18-25.

Polat S, Hocaoğlu Ç. Migren tipi baş ağrısının psikiyatrik yönü. Klin Tıp Bil Derg 2018; (6)1.

Russel MB, IversonHK, Olesen J. Improved description of the migraine aura with a headache diary. Cephalalgia 1994; 14:107-7.

Salomone S., Caraci F., Capasso A. Migraine. Open Neurol J 2009;3:64-71.

Sönmezler A, Ünal İ, Yoldaş TK. Migren ve gerilim tipi baş ağrısının sağlığa ilişkin yaşamkalitesi üzerine etkileri. Çukurova Med J 2013; 38-3:374-81.

Tombul K, Balcığlu İ, Ertem DH, Bingöl A, Göksan B, Uludüz DU. Migren Tipi BaşağrısıOlan Olgularda Kişilik Özellikleri. Yeni Symposium 2015:2.

Ünal M. Migren kökenli baş ağrısında spinal manipülasyon tedavisinin ağrı üzerine etkisinin araştırılması: Olgu Sunumu. İzmir Kâtip Çelebi Üniv Sağ Bil Fak Derg 2016; 1(3):51-3

Yağmur M, Sevinçer GM, Kandeğer A, Duygu Ç. Cerrahi tedavi arayışı olan migren hastalarında anksiyete. Klinik Psikiyatri 2019;22:169-74.

Yavuz KF, Yavuz N, Ulusoy S, Alnıak İ, Hafize N, Güneş $\mathrm{G}$. Gerilim ve migren tipi baş ağrılarına eşlik eden işlevsel olmayan bilişsel içerikler ve tutumlar. J Psychiatr Neurol Sci 2013;26:12-21.

Younger DS. Epidemiology of migraine. Neurol Clin 2016;34(4):849-61. 